\title{
Numerical Simulation of Heat Transfer Using Cooling Roof Panels
}

\author{
Katarína Kaduchováa ${ }^{1, *}$, Richard Lenhard ${ }^{1}$, and Milan Malcho ${ }^{1}$ \\ ${ }^{1}$ University of Žilina, Faculty of Mechanical Engineering, Department of Power Engineering, \\ Univerzitná 8215/1, 01026 Žilina, Slovak republic
}

\begin{abstract}
Roof cooling can be used in coffered roofs, acoustic panels, as active cooling plasterboard attached to a standard metal structure designed for lowered roofs, or as a system of cooling register under the plaster. The roof cooling system works on the principle of heat transfer through a large active area and there is no unpleasant air flow than with conventional air conditioning. For technological reasons, very often pipes with a heat transfer medium are attached to a sheet metal of various materials, the thermokinetic properties of which significantly influence the intensity of the heat flux dissipated by the cooling system. The paper presents a numerical analysis of heat transport using stainless steel and aluminium sheets as the supporting sheet, as well as the influence of different ways of installing large panels under the roof.
\end{abstract}

\section{Introduction}

The roof cooling system works on the principle of heat transfer through a large active surface. At present, there are a number of roof cooling systems that provide draft-free heat dissipation from internal spaces intensely loaded with heat from the exterior and thus create a comfortable environment in these spaces for living and working. Roof cooling can be used in coffered roofs, acoustic panels, as active cooling plasterboard attached to a standard metal structure designed for lowered roof, or as a system of cooling register under the plaster. The roof cooling system works on the principle of heat transfer through a large active surface. There is no unpleasant air flow than with conventional air conditioning, so you feel more comfortable and avoid health problems caused by drafts. For technological reasons, very often pipes with a heat transfer medium are attached to a sheet of different material, the thermokinetic properties of which significantly affect the intensity of the heat flux.

\footnotetext{
*Corresponding author: katarina.kaduchova@,fstroj.uniza.sk
} 


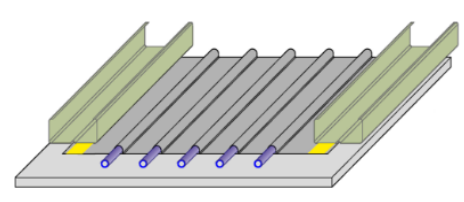

a)

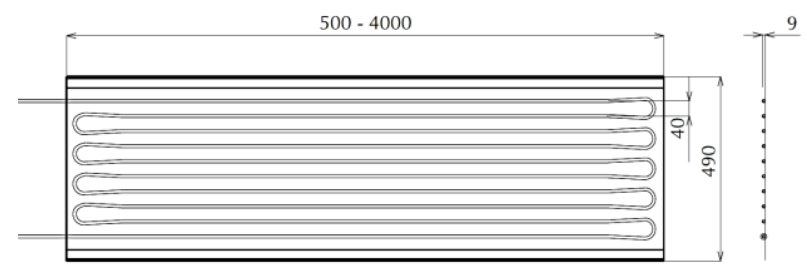

b)

Fig. 1. Storage of collector plates with pipes (a) on a plasterboard panel (b).

All methods of heat transport are involved in the transport of heat from the interior to the cooling medium, i. j. radiation, natural and forced convection and heat conduction with consideration of complex thermal resistance during heat transfer from the interior to the heat transfer medium flowing in a tube fixed by pressing in the collector plate $[1,2]$. Heat flow from the interior passes through the boundary layer on the plasterboard panel by natural convection into the panel, conduction through the wall of the panel to contact the plasterboard panel with sheet metal, conduction to the contact surface of five-layer polybutene pipe with oxygen barrier with sheet metal, conduction to the inner wall medium and by its flow into the heat exchanger. Due to the complicated geometry of heat transport, numerical analysis of heat transport was performed by the above-mentioned heat dissipation system using stainless steel and aluminium sheet as the support sheet.

\section{Heat flow in a large-area cooling system}

In a heat transport system for cooling the interior with large panels (Figure 1), the heat transfer intensity is mainly influenced by the thermal resistance of the plasterboard, the thermal resistance of the support plate, the contact of the pipe with the support plate and the thermal resistance of the polybuthene pipe [3]. Due to the standard design of the large-area roof cooling system and the technology of production of supporting sheets, the influence of the sheet material on the total dissipated heat flow under the same boundary conditions was determined by means of numerical simulation. Aluminium and AISI 304 steel sheets were used as the material of the support and distribution plate (Figure 2).
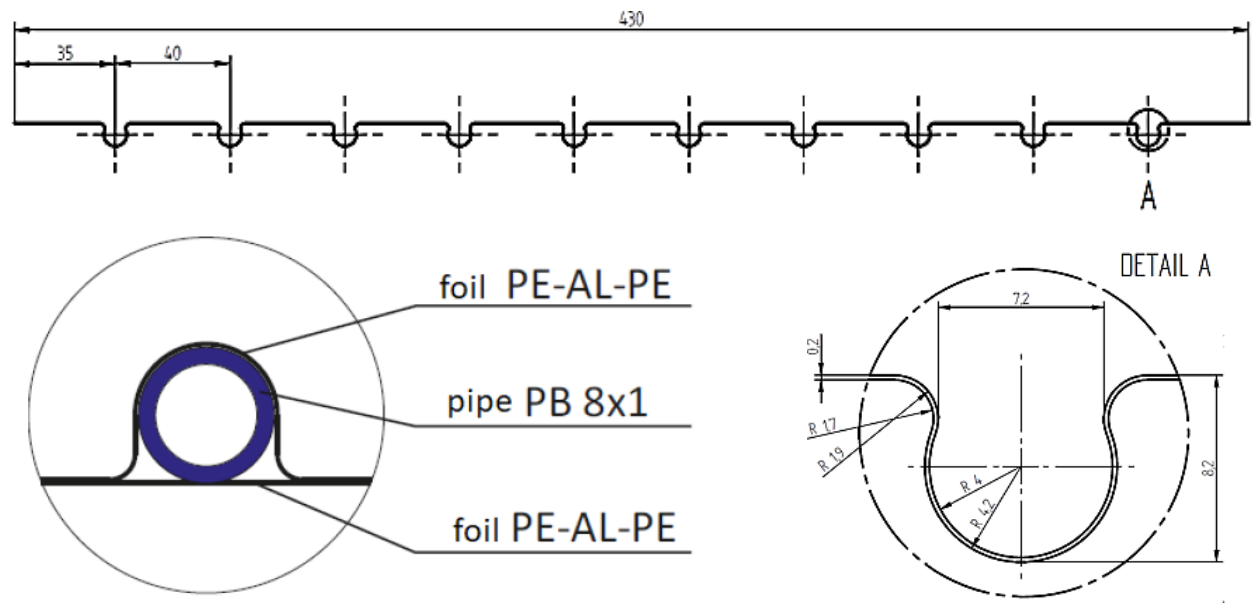

Fig. 2. Dimensions and shape of the support plate with the tube deposition. 
Heat transfer by the air cavity (closed volume) above the support plate is solved as heat transfer by natural convection in the cavity [1]. This heat flow does not contribute to the transport of heat from the interior.

\section{Numerical modelling of heat and temperature field transfer in a ceiling cooling system located in a test room}

The cooling capacity of the device under test is determined at steady state by measuring the cooling water flow and increasing its temperature. The cooling capacity can be presented as a function of the temperature difference between the reference room temperature and the mean cooling water temperature.

The measurement is performed in an airtight room with certain parameters, which are determined by the European standard STN EN 14240: 2004 [4], with a controllable temperature on the interior surfaces and with a negligible heat flux in the room. Equilibrium cooling capacity of the tested equipment, heat supplied to the test room by means of electric heaters distributed differently on the floor in the test room.

For the purpose of creating a numerical simulation of heat transport during interior cooling by large panels, a simplified 2D model of a roof cooling system located in a test room created according to the dimensions defined in STN EN 14240: 2004 (Figure 3) was created.

1. Water wall

2. Thermal insulation

3. Test sample

4. Corner insulation

5. Heat source simulator

6. Air temperature measuring point

7. Measuring point for measuring general temperature

8. Measuring point for measuring the temperature under insulation
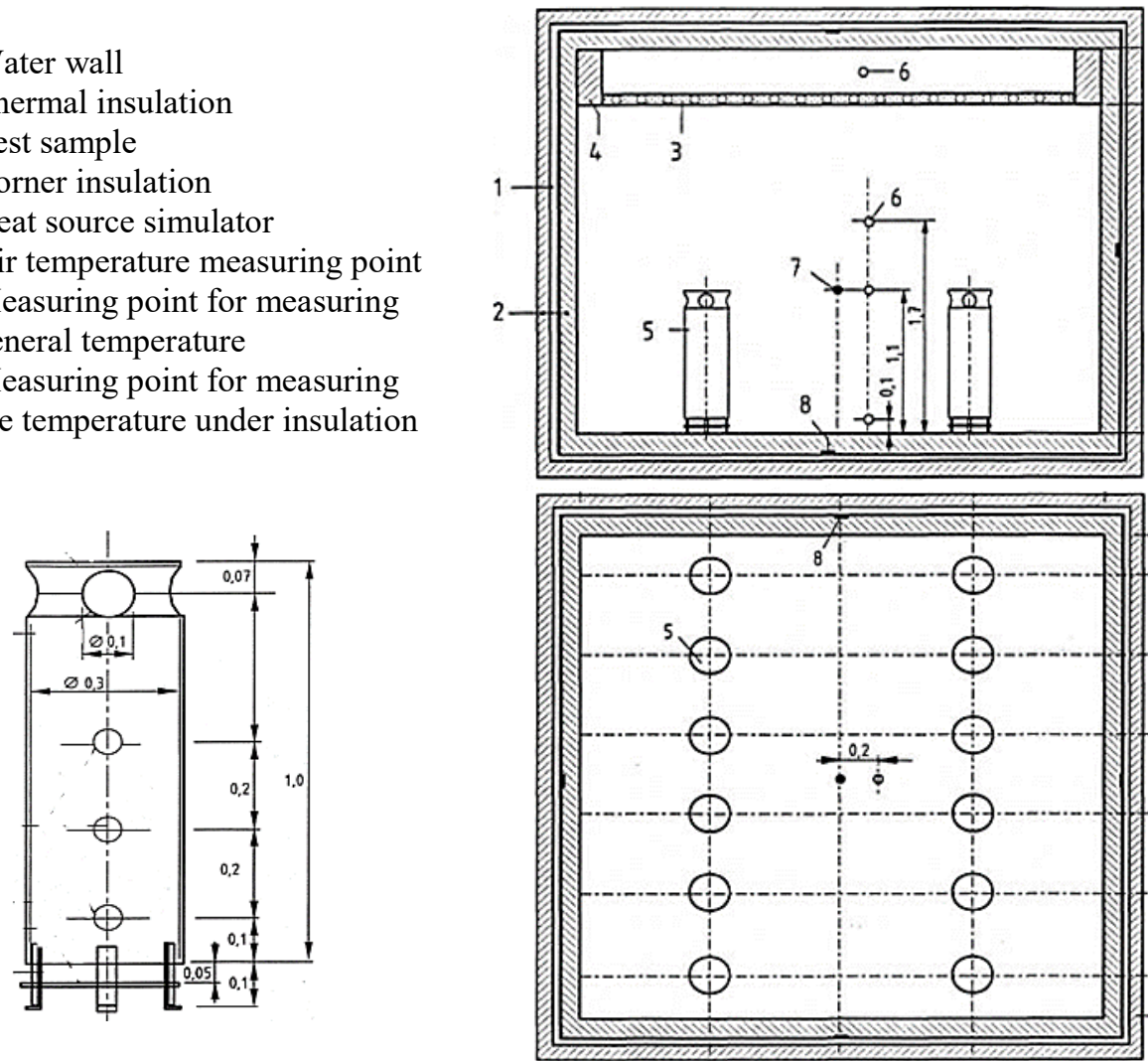

Fig. 3. Example of test room and measuring points [4]. 
The modelling of heat flow and temperature fields is based on the steady state at an interior wall temperature of $26^{\circ} \mathrm{C}$ and inlet and outlet cooling water temperatures of $16^{\circ} \mathrm{C} / 19^{\circ} \mathrm{C}$ (defined in STN EN 14240: 2004), using an aluminium support plate and stainless steel sheet AISI 304 without thermal insulation and with thermal insulation of the sheet by the cavity side with Isover domo comfort insulation $10 \mathrm{~mm}$ thick, density $\rho=11.5 \mathrm{~kg} / \mathrm{m}^{3}$ and thermal conductivity $\lambda_{I s o}=0.039 \mathrm{~W} / \mathrm{mK}$ The thickness of the plasterboard (SDK) was $10 \mathrm{~mm}$ and its thermal conductivity $\lambda_{S D K 1}=0.25 \mathrm{~W} / \mathrm{m} . \mathrm{K}$ and $\lambda_{S D K 2}=0.45 \mathrm{~W} / \mathrm{m}$.K. The surface temperature of the walls of the simulated volume was $26^{\circ} \mathrm{C}$. In the space of the calculated volume, the natural convection was generated by the temperature difference of the ceiling and the walls (Figure 4).

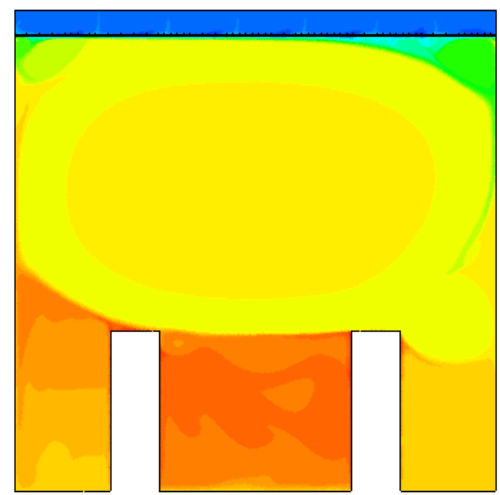

Support plate Aluminium, $0.2 \mathrm{~mm}$, uninsulated

$\lambda_{S D K I}=0.25 \mathrm{~W} / \mathrm{m} . \mathrm{K}, q=61.37 \mathrm{~W} / \mathrm{m}^{2}$, $t_{\text {int }}=26.01^{\circ} \mathrm{C}$

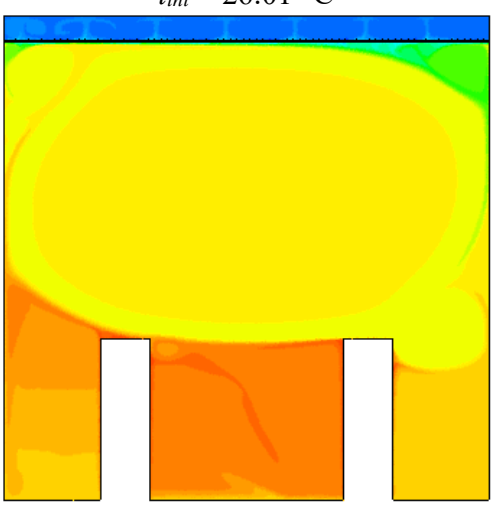

Support plate Aluminium, $0.2 \mathrm{~mm}$, uninsulated

$\lambda_{S D K I}=0.45 \mathrm{~W} / \mathrm{m} . \mathrm{K}, q=69.99 \mathrm{~W} / \mathrm{m}^{2}$, tint $=25.97{ }^{\circ} \mathrm{C}$

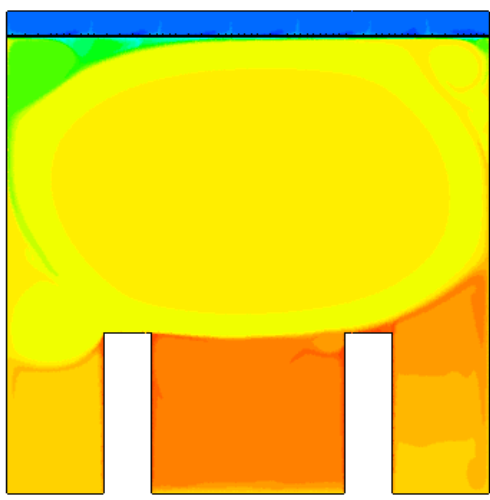

Support plate AISI 304, $0.2 \mathrm{~mm}$, uninsulated $\lambda_{S D K l}=0.25 \mathrm{~W} / \mathrm{m} . \mathrm{K}, q=53.26 \mathrm{~W} / \mathrm{m}^{2}$, $t_{\text {int }}=25.98^{\circ} \mathrm{C}$

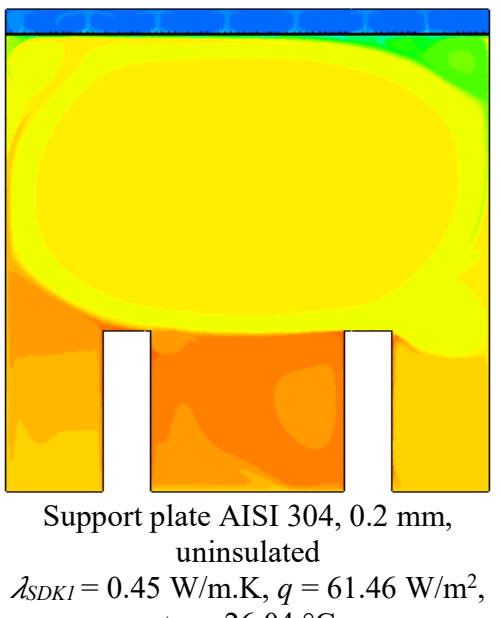
$t_{\text {int }}=26.04^{\circ} \mathrm{C}$

Fig. 4. Results of numerical modelling of heat transfer and temperature field in a roof cooling system.

\section{Conclusion}

Simulations of heat transfer from the interior to the cooling water as a combined heat transfer by radiation, natural convection and conduction to visible plasterboards, on which load-bearing heat-insulated or insulated sheets for $8 \times 1 \mathrm{~mm}$ butylene pipes with cooling 
heat transfer medium are mounted, have shown that it is possible to optimize the composition of the roof cooling system [3]. The optimization criterion was the maximum heat flux density depending on the combinations of different support plate materials (aluminium, AISI 304 steel), gypsum board material (thermal conductivity), support plate thickness and insulation of the pipe system built into the support plates with Isover mineral wool. The support plates of the tubes also have the function of membranes dissipating heat to the outer wall of the butane tube. This heat transfer takes place by conduction in the support plate and its intensity also depends on the heat loss by heat transfer to the cavity between the roof and the support plate. A comparison of the heat flux densities of thermally uninsulated sheet steel made of AISI 304 steel and $0.2 \mathrm{~mm}$ thick aluminum shows a significant effect of the thermal conductivity of the material on the thermal conductivity density of the roof cooling system, $q=53.26 \mathrm{~W} / \mathrm{m}^{2}$ at AISI 304 and $q=61.37 \mathrm{~W} / \mathrm{m}^{2}$ for aluminium sheet. The effect of the thermal conductivity of a plasterboard will be similar. With a plasterboard (SDK) plate of $10 \mathrm{~mm}$ and its thermal conductivity $\lambda_{S D K l}=0.25 \mathrm{~W} / \mathrm{m} . \mathrm{K}$ a $\lambda_{S D K 2}=0.45 \mathrm{~W} / \mathrm{m} . \mathrm{K}$ is the heat flux density with an aluminium support plate $q=61.37 \mathrm{~W} / \mathrm{m}^{2}$, resp. $q=69.99 \mathrm{~W} / \mathrm{m}^{2}$. As numerical simulations of the roof cooling system have shown, this heat flux density can be slightly increased by simply modifying the system - by insulating the support plate from the cavity side with thermal insulation from light mineral wool Isover domo comfort $10 \mathrm{~mm}$ thick, density $\rho=11.5 \mathrm{~kg} / \mathrm{m}^{3}$ and thermal conductivity $\lambda_{I s o}=0.039 \mathrm{~W} / \mathrm{m} . \mathrm{K}$ (Figure 5). By such an adjustment, it is possible to increase the density of the dissipated heat flux to $q=71.23 \mathrm{~W} / \mathrm{m}^{2}$ for aluminium sheet. Modelling of combined complex heat through geometrically non-trivial bodies using numerical simulation has shown that such a way of optimizing the thermal performance of roof cooling systems is significantly faster and more efficient than experimental development.
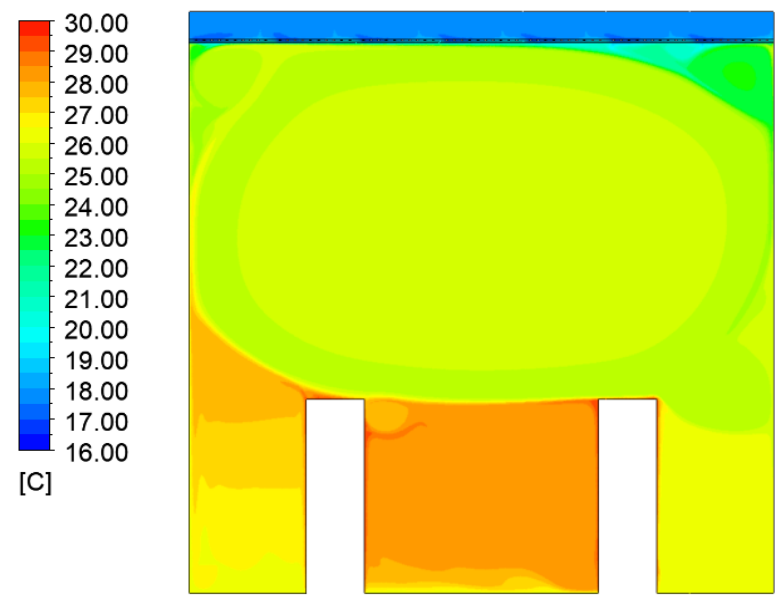

Support plate Aluminium, $0.2 \mathrm{~mm}$, isolated $-\lambda_{I s o}=0.039 \mathrm{~W} / \mathrm{m} . \mathrm{K}$ $\lambda_{S D K I}=0.45 \mathrm{~W} / \mathrm{m} . \mathrm{K}, q=71.23 \mathrm{~W} / \mathrm{m}^{2}$, $t_{\text {int }}=26.08^{\circ} \mathrm{C}$

Fig. 5. The result of numerical modelling of heat transfer and temperature field in a roof cooling system.

Acknowledgements: This work was founded by projects KEGA 063ŽU-4/2018 The storage of hydrocarbon gases in hydrate structures as an alternative method of energy accumulation.

This work was supported by Grant System of University of Zilina No. 1/2020. (8024). 


\section{References}

1. F. P. Incropera, D. P. Dewitt, T. L. Bergman, A. Lavine, Fundamentals of heat and mass transfer (John Wiley, New York, 2007)

2. O. G. Martynenko, P. P. Khramtson, Free - convective heat transfer (Springer, New York, 2005)

3. A. Kapjor, R. Lenhard, (Published by University of Žilina, Transcom, 2007)

4. STN EN - 140240 Ventilation for buildings - Chilled ceilings - Testing and rating, Brussels (2004)

5. N. Kantova, J. Jandacka, M. Holubcik, A. Caja, 36th Meeting of departments of fluid mechanics and thermodynamics 1889 (2017)

6. L. Dabek, A. Kapjor, L. J. Orman, MATEC Web of Conferences 168, 07001 (2018)

7. P. Durcansky, M. Patsch, J. Jandacka, AIP Conference Proceedings 1745 (2016)

8. M. Novomestsky, R. Banovcan, A. Kapjor, H. Smatanova, MATEC Web of Conferences, 168 (2018)

9. R. Pastircak, J. Scury, M. Bruna, et al., Archives of foundry engineering, 17 (2017)

10. Z. Vaszi, J. Šváb, A. Varga, G. Jablonský, J. Kizek, L. Lazić, The holistic approach to environment. 1, 3 (2011) 